\title{
Method of fuzzy controller adaptation
}

\author{
Muravyova E. A. \\ Ufa State Petroleum Technological University, Branch \\ in Sterlitamak \\ Sterlitamak, Russia \\ muraveva_ea@mail.ru
}

\author{
Sharipov M. I. \\ Ufa State Petroleum Technological University, Branch \\ in Sterlitamak \\ Sterlitamak, Russia \\ muraveva_ea@mail.ru
}

\begin{abstract}
During writing this work, the fuzzy controller with a double base of rules was studied; it was applied for the synthesis of the automated control system. A method for fuzzy controller adaptation has been developed. The adaptation allows the fuzzy controller to automatically compensate for parametric interferences that occur at the control object. Specifically, the fuzzy controller controlled the outlet steam temperature in the boiler unit BKZ-75-39 GMA. The software code was written in the programming support environment Unity Pro XL designed for fuzzy controller adaptation.
\end{abstract}

Keywords - fuzzy controller, adaptation, values, temperature, steam.

\section{INTRODUCTION}

In today's world, it is impossible to find an area where electricity would not be used. All equipment at any enterprise particularly in mechanical engineering operates on electricity obtained from a combined heat and power plant. To produce electricity, a superheated steam produced by boilers is used, which enters turbines where mechanical energy is converted into electrical energy.

Also steam is widely used to control a steam-air hammer. Depending on the nature of the distribution of the operating periods of the energy source, the hammer can operate in several modes: successive automatic blows; single blows with an upper pause; also there is a swing cycle operating automatically.

Thus, one can conclude that for different operating modes of the hammer, steam with different temperatures and different pressures is needed. The steam used in a production process is produced by boiler units. That is why, it is important to develop a control system of a boiler unit which allows one to obtain steam of desired temperature and pressure.

\section{ADVANTAGES OF FUZZY CONTROL}

The main advantages of fuzzy control is the applicability of expert knowledge in an explicit form, high speed, smooth implementation of multidimensional essentially nonlinear dependencies.

The fuzzy controller is a multidimensional nonlinear static element. To synthesize the fuzzy controller, it is sufficient to determine its desired static characteristic and configure it so that it coincides with the desired one $[2-4]$. Now a problem arises since the fuzzy controller is not precise. To solve this problem, the fuzzy controller with double base of rules has been developed.

Due to changes in the fuzzy controller structure, the task of developing the algorithm of its synthesis has emerged. This article considers two algorithms of the fuzzy controller synthesis, the synthesis using reference points and the fuzzy controller training.

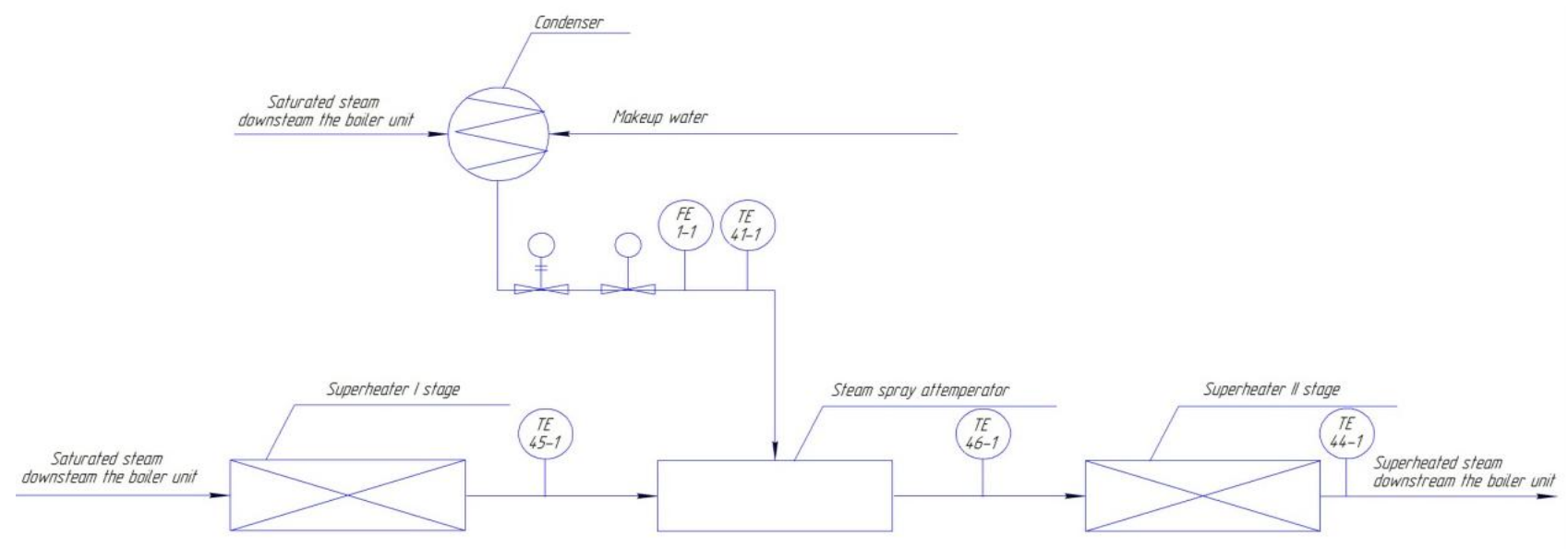

Fig. 1.Process diagram 


\section{FUZZY CONTROLLER WITH DOUBLE BASE OF RULES}

The fuzzy controller with double base of rules can be represented as two classic fuzzy controllers which use the similar linguistic variables. The static characteristic of one of them is always slightly below the desired characteristic, and the second one is a little higher. These fuzzy controllers can be visualized in the form of two "experts" (fig. 2), one of which always decreases the control action, and the second one always increases it a little. When one is on the desired static characteristic and look at these "experts", one sees them on the opposite sides. "Experts" are beginning to "argue"; as a result, they arrive at a solution that will be closer than each of them to the desired value. If one enters a "referee" system in the process of "dispute", it will begin to trust more in some of the "experts". If "referee" is right, the "experts" will arrive at the desired solution. The weights of the individual rules can be used as "referee".

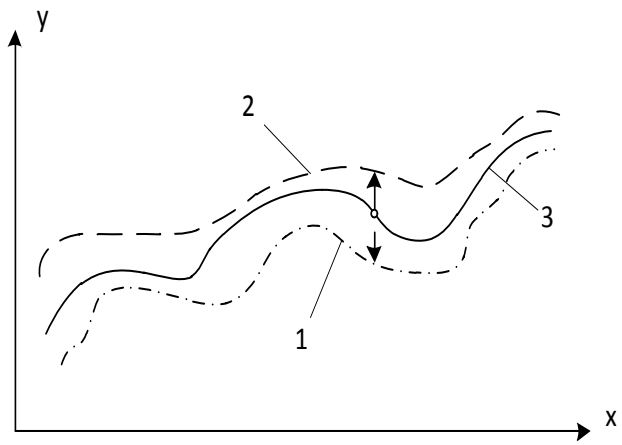

Fig. 2. Fuzzy inference with two «experts».

$1-\langle$ Expert $1 », 2-\langle$ Expert $2 »$,

3 - desired static characteristic.

As a result, while maintaining high performance the fuzzy control can be obtained with precision governed by the computer system on which it runs. This new quality can be explained by dialectic law of unity and conflict of opposites. Unity is the single structure, goals, input data, similar result. The conflict of opposites is that each base of rules pulls the result in different direction with respect to the desired one.

Before starting the synthesis of the fuzzy controller (FC) it is essential to develop its conceptual models for each output. The conceptual model shows the effect of the input signals (sensor values) on the result of the fuzzy controller - the value of its output. This model can be represented either graphically (fig. 3) or analytically.

In the analytical form, it is sufficient to represent dependence of the output on the input as follows (for the same FC):

$$
y_{2}=f\left(x_{1}, x_{2}, x_{4}\right)
$$

In either case, one needs to specify only the FC inputs, which should have an impact on its output. At the same time, it is possible that FC input, if need be, should be supplied with the values of its outputs, as well as derivatives (or increments of a value for 1 cycle) $\mathrm{FC}$ inputs to impart certain dynamic properties to FC.

After compiling all the conceptual models, they can be combined into the fuzzy controller. If the inputs of various FC mismatch, the advisability of combining should be checked experimentally (the system performance is selected as a criterion).

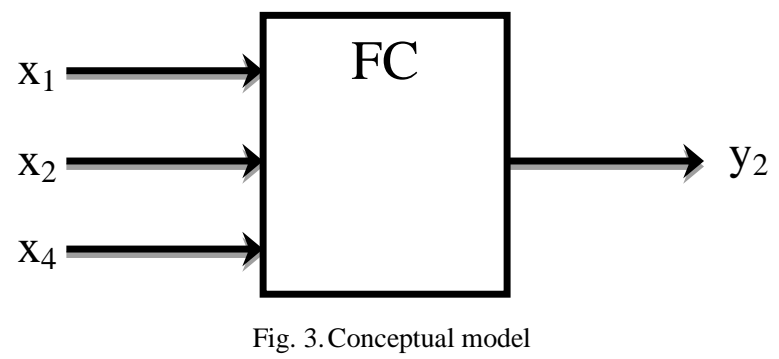

IV. GATHERING EXPERT INFORMATION

Expert information gathering is possible in two ways:

1) Conducting an experiment;

2) Analysis of existing information.

In either case, it is necessary to describe the measuring ranges of all the parameters involved in FC. After that, in each range from five to seven, values are selected (reference points). The maximum and minimum FC input values are always the reference points.

In the case of the experiment being conducted, these values can be distributed evenly or if there are extreme points or the points of significant variation in influencing the output, then the abscissa values of these points are taken into account. After one selects all the reference points the optimal values of FC, outputs should be selected by performing an experiment. The experiment can be computer-aided, if there is a welldescribed mathematical model.

In the analysis of existing data (experimental data), the reference points are selected by breaking the values of input signals into groups. In extreme groups as reference points, both minimum and maximum values for the left and right groups are selected as reference points, respectively. For other groups, their average reference points are selected. When filling the table of reference points, the value of the nearest point in the experimental data is taken as the value of the output. As the nearest point, it is possible to take the expected value, using the apparatus of mathematical statistics or a point having the shortest distance to the reference point. It is also possible to synthesize the Mamdani fuzzy controller. After synthesis of the FC, its training using experimental data is to be conducted.

As a result of gathering expert information for each FC, the table of reference points can be obtained (Table I). The table of reference points should describe the whole area of FC inputs. In the example, the FC input ranges vary from 0 to 10. The table of reference points consists of two parts: the left one describing the inputs, the right one describing the outputs. 
TABLE I. Table of reference points

\begin{tabular}{|c|c|c|c|c|}
\hline $\mathrm{x}_{1}$ & $\mathrm{x}_{2}$ & $\mathrm{x}_{4}$ & $\mathrm{y}_{2}$ & $\mathrm{y}_{5}$ \\
\hline 0 & 0 & 0 & 5 & 0 \\
\hline 0 & 0 & 2 & 0 & 3 \\
\hline$\cdots$ & $\cdots$ & $\cdots$ & $\cdots$ & $\cdots$ \\
\hline 10 & 10 & 10 & 1 & 5 \\
\hline
\end{tabular}

In the event that it is impossible to fill all of the reference points, the FC output value should be based on the condition of monotony and smoothness of static characteristic. That is, it is necessary to see the value of adjacent reference points and select a value that lies between them.

\section{DESCRIPTION OF THE LINGUISTIC VARIABLES}

FC input and output linguistic variables are to be described by a range of crisp values and membership functions for each term.

In order to get smooth static characteristics, it is convenient to use triangular-shaped terms.

For the input terms, the apex of the membership function triangle is located at the reference point while its base connects the neighboring reference points adjacent to the apex.

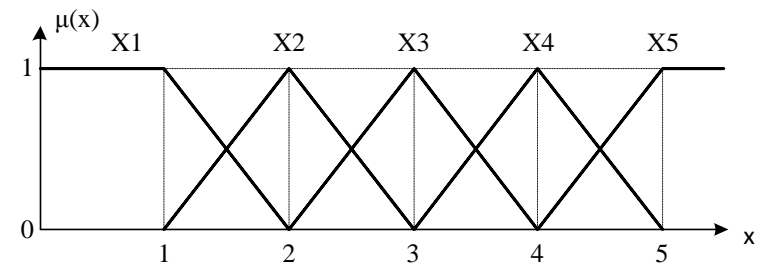

Fig. 4. Input linguistic variable

For output variables, the location of the apex of membership functions triangles needs to be selected. The shape of the outer membership functions must always be symmetrical

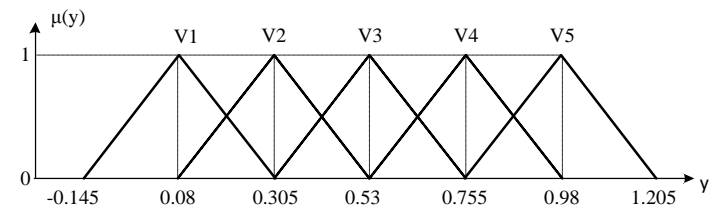

Fig. 5. Output linguistic variable

\section{SYNTHESIS OF THE FUZZY CONTROLLER BASED ON THE REFERENCE POINTS}

Synthesis of the fuzzy controller with preset static characteristic can be broken into the following stages [5 - 9]:

1) the formation of linguistic variables for each input and output signals;

2) selection of defuzzification, aggregation, activation and accumulation algorithms;

3) synthesis of the production rules system.
Formation of linguistic variables, the choice of defuzzification, aggregation, activation and accumulation algorithms are determined by an expert based on the characteristics of the control object, personal experience and expert preferences and is described in the literature [5-10].

The initial data for the design of the fuzzy controller with double base of rules are the desired static characteristic, the variation range of the input and output signals. The desired static characteristic is represented as the table of reference points.

The obtainment of the desired static characteristics can be broken into the following stages:

1) determination ranges for variation of the fuzzy controller input variables;

2) partitioning varying range into intervals by selecting from five to seven input variable values;

3) for all possible combinations, the desired output value of the fuzzy controller is to be defined.

\section{CREATION OF THE PROCESS MODEL}

Fuzzy controllers generate control signals based on the application of the fuzzy logic [1]. Over the years, fuzzy controllers have been of still greater use in modern automatic control systems [2]. Fuzzy controllers can be used to control all the parameters of complex process objects. In this paper, the fuzzy controller is used to control one of the parameters of process in production of superheated steam in the boiler unit BKZ-75-39 GMA. The boiler unit outlet steam temperature is selected as a parameter, which value is chosen for controlling the valve opening gap. Since this parameter could be influenced by parametric interferences, such as change in boiler steam-generating capacity and, therefore, change in steam temperature behind the first stage of superheater, as well as change in condensate temperature, it is then presumed as necessary for the fuzzy controller to be capable, while unattended, to automatically compensate for the abovementioned interferences.

In that way, the main objective in this paper is the synthesis and the fuzzy controller adaptation. The fuzzy controller adaptation is designed so that it could be controlled automatically in a way to match parametric interferences.

Steam temperature $t_{\text {outlet steam }}$ is controlled by varying the injection flow rate of "internal" condensate into the steam cooler located between the first and second stages of the superheater. The condensate "injection" flow rate is varied with the $6 \mathrm{C}-13-1$ control valve. The $6 \mathrm{C}-13-1$ valve opening gap depends on the steam temperature behind the first stage of superheater $t_{s}$, on the steam temperature behind the second stage of superheater $\mathrm{t}_{\text {outlet steam; }}$ that is to say, on the final steam temperature and on the condensate temperature $t_{c}$, respectively.

To adjust the fuzzy controller adaptation, one must have a clear idea of how the process works, i.e. a model should be built which could characterize the steam spray attemperator operation. The model was constructed using a regression analysis, a statistical method of research. This is the most 
widely used technique to show the dependence of any of parameters on one or more independent variables. Thus, it is possible to use a regression model to show the impact of three parameters: the steam temperature downstream the attemperator first stage $t_{s I}$, condensate temperature $t_{c}$ and valve opening gap $a(\%)$ on the outlet steam temperature.

Let us build a regression model in MS Excel, using data from Table II describing the outlet steam temperature variation at steam temperature $\mathrm{t}_{\text {sIst }}=360,380,400^{\circ} \mathrm{C}$, at the condensate temperature $\mathrm{t}_{\mathrm{c}}=50,80,110^{\circ} \mathrm{C}$, at the valve gap opening $\mathrm{a}=0 . . .100 \%$.

TABLE II. THE DETERMINATION OF OUTLET STEAM TEMPERATURE AT TC $=50^{\circ} \mathrm{C}$

\begin{tabular}{|c|c|c|c|c|c|}
\hline$\alpha, \%$ & 50 & 75 & 100 \\
\hline 360 & & & & & \\
380 & 360 & 350 & 330 & 315 & 310 \\
400 & 400 & 375 & 360 & 350 & 330 \\
\hline
\end{tabular}

From the regression model, the following equation has been obtained:

$$
\mathrm{y}=3.33+1,1 * \mathrm{x}_{1}-0.48333 * \mathrm{x}_{2}-0.81556 * \mathrm{x}_{3},
$$

where $X_{1}$ - the steam temperature behind the first stage of superheater $t_{\text {sIst }}$,

$\mathrm{X}_{2}$ - the condensate temperature $\mathrm{t}_{\mathrm{c}}$;

$\mathrm{X}_{3}$ - the valve opening gap $\mathrm{a}$;

y- steam temperature behind the second stage of superheater $t_{\text {sII }}$.

The model has been obtained based on 45 design points, which will determine the valve opening gap. This number has come out as a result of multiplying the number of the fuzzy controller input parameters in a developing model (1); i.e., 3 values of the steam temperature behind the first stage of steam cooler $\mathrm{t}_{\text {sIst }}\left(360,380,400^{\circ} \mathrm{C}\right) ; 3$ values of the condensate temperature $\mathrm{t}_{\mathrm{c}}\left(50,80,100^{\circ} \mathrm{C}\right) ; 5$ values of the valve opening gap $\alpha(0,25,50,75,100)$.

Condensate temperature $t_{c}$, steam temperature $t_{\text {sIst }}$ and valve opening gap 6C-13-1 are influenced by the boiler unit steam-generating capacity, which can look like 55, 60, 65, 70, 75 tons per hour. This parameter is not going to be considered in calculation as with this value considered $625\left(5^{4}=625\right)$ production rules could be obtained. The calculation will be effected with the boiler unit steam-generating capacity 70 tons per hour, because it is most often occurring steam-generating capacity in the boiler unit of this type. Similarly, it is possible to carry out calculations for other values of the boiler unit steam-generating capacity as well.

The fuzzy controller input will be supplied with steam temperature $t_{\text {sIst }}$ coming from the superheater first stage and condensate temperature $t_{c}$. Valve opening gap a in percentage represents the fuzzy controller output variable by means of which the steam temperature is exactly controlled.

\section{VIII.THE FUZZY CONTROLLER SYNTHESIS}

The built conceptual model of the fuzzy controller determines which parameter values must be put together for the fuzzy controller to function properly in the process of the expert information gathering. As a result of the above process, the reference points table for the fuzzy controller was derived (Table III). This table describes the entire scope of the fuzzy controller inputs and outputs. This table is constructed based on experimental data.

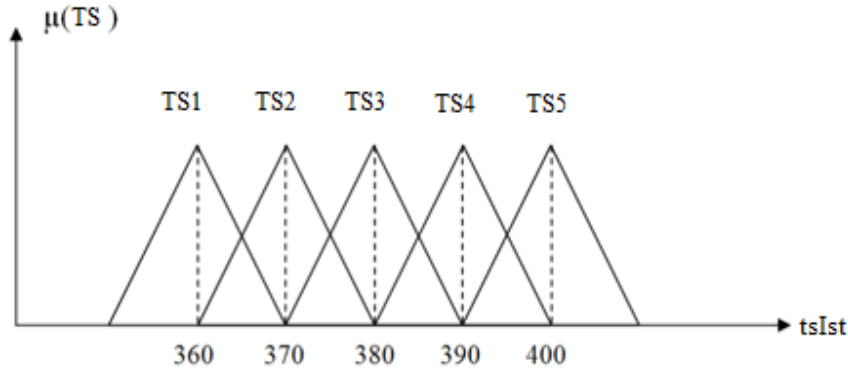

Fig. 6. Input linguistic variable $t_{\text {sIst }}$.

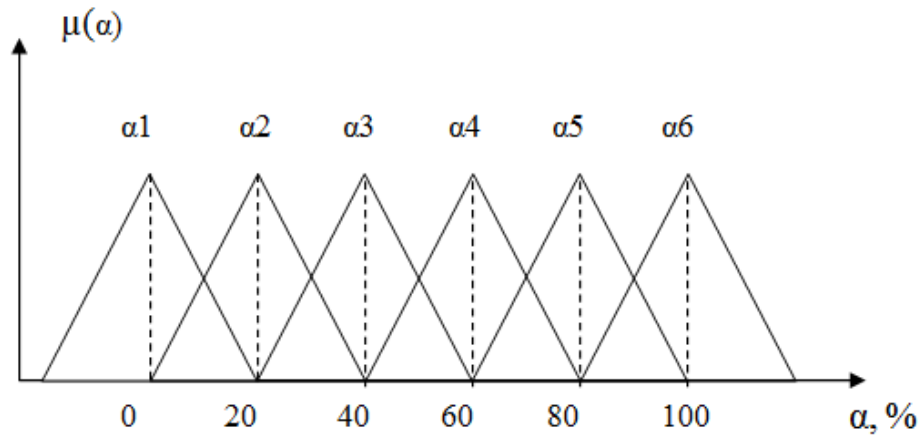

Fig. 7. Output linguistic variable for the valve opening gap a

TABLE III. TABLE OF REFERENCE POINTS

\begin{tabular}{|c|c|c|c|c|c|}
\hline $\begin{array}{c}\mathrm{t}_{\mathrm{vI}} \\
\mathrm{t}_{\mathrm{c}}\end{array}$ & 360 & 370 & 380 & 390 & 400 \\
\hline 50 & 20 & 20 & 20 & 20 & 20 \\
55 & 40 & 20 & 20 & 20 & 20 \\
60 & 60 & 20 & 20 & 20 & 20 \\
65 & 80 & 40 & 20 & 20 & 20 \\
70 & 100 & 60 & 20 & 20 & 20 \\
75 & 100 & 80 & 40 & 20 & 20 \\
80 & 100 & 100 & 60 & 20 & 20 \\
85 & 100 & 100 & 80 & 40 & 20 \\
90 & 100 & 100 & 100 & 60 & 20 \\
95 & 100 & 100 & 100 & 80 & 40 \\
100 & 100 & 100 & 100 & 100 & 60 \\
105 & 100 & 100 & 100 & 100 & 80 \\
110 & 100 & 100 & 100 & 100 & 100 \\
\hline
\end{tabular}

The next step in the fuzzy controller synthesis is the determination of linguistic variables inputs and outputs, which variables are described by the range of current values and by membership functions for each of the terms. A triangular shape terms are used to describe the input linguistic variables, the vertex of which is located at the reference point, the base is located between the two nearest reference points [2]. Terms 
applied are triangular shape because they help to obtain smooth static characteristics.

Furthermore, the production rule synthesis must be carried out by means of creating table of desired values for the fuzzy controller output variable, that is valve opening gap $\alpha$, for each value - the steam temperature $t_{\text {sIst }}$ and condensate temperature $\mathrm{t}_{\mathrm{C}}$ term.

Production rules were constructed from Table IV (Table V). 65 production rules were obtained. This number has come out as a result of multiplying the number of the fuzzy controller terms input variables $(5 * 13=65)$, i.e. 5 values of the steam temperature behind the first stage of steam cooler $t_{\text {sIst }}$ $\left(360,370,380,390,400^{\circ} \mathrm{C}\right), 13$ value of the condensation temperature $t_{c}(50,55,60,65,70,7580,85,90,95,100,105$, $110^{\circ} \mathrm{C}$ ). These rules determine which of the consequents are basic or additional; the truth degree is determined for additional consequent. Both the technique of determining consequents and their truth degrees are described in [3].

TABLE IV. THE DESIRED VALUES OF THE VALVE OPENING GAP A

\begin{tabular}{|l|c|c|c|c|c|c|c|}
\hline № & $\mathrm{t}_{\text {пI }}$ & $\mathrm{t}_{\mathrm{k}}$ & $\alpha$ & № & $\mathrm{t}_{\text {п1 }}$ & $\mathrm{t}_{\mathrm{K}}$ & $\alpha$ \\
\hline 1 & $\mathrm{~T}_{\mathrm{s} 1}$ & $\mathrm{~T}_{\mathrm{c} 1}$ & 23 & 10 & $\mathrm{~T}_{\mathrm{s} 1}$ & $\mathrm{~T}_{\mathrm{c} 10}$ & 94 \\
2 & $\mathrm{~T}_{\mathrm{s} 1}$ & $\mathrm{~T}_{\mathrm{c} 2}$ & 36 & 11 & $\mathrm{~T}_{\mathrm{s} 1}$ & $\mathrm{~T}_{\mathrm{c} 11}$ & 93 \\
3 & $\mathrm{~T}_{\mathrm{s} 1}$ & $\mathrm{~T}_{\mathrm{c} 3}$ & 58 & 12 & $\mathrm{~T}_{\mathrm{s} 1}$ & $\mathrm{~T}_{\mathrm{c} 12}$ & 91 \\
4 & $\mathrm{~T}_{\mathrm{s} 1}$ & $\mathrm{~T}_{\mathrm{c} 4}$ & 82 & 13 & $\mathrm{~T}_{\mathrm{s} 1}$ & $\mathrm{~T}_{\mathrm{c} 13}$ & 92 \\
5 & $\mathrm{~T}_{\mathrm{s} 1}$ & $\mathrm{~T}_{\mathrm{c} 5}$ & 98 & 14 & $\mathrm{~T}_{\mathrm{s} 2}$ & $\mathrm{~T}_{\mathrm{c} 1}$ & 22 \\
6 & $\mathrm{~T}_{\mathrm{s} 1}$ & $\mathrm{~T}_{\mathrm{c} 6}$ & 93 & 15 & $\mathrm{~T}_{\mathrm{s} 2}$ & $\mathrm{~T}_{\mathrm{c} 2}$ & 21 \\
7 & $\mathrm{~T}_{\mathrm{s} 1}$ & $\mathrm{~T}_{\mathrm{c} 7}$ & 96 & $\ldots$ & $\ldots$ & $\ldots$ & $\ldots$ \\
8 & $\mathrm{~T}_{\mathrm{s} 1}$ & $\mathrm{~T}_{\mathrm{c} 8}$ & 99 & 64 & $\mathrm{~T}_{\mathrm{s} 5}$ & $\mathrm{~T}_{\mathrm{c} 12}$ & 77 \\
9 & $\mathrm{~T}_{\mathrm{s} 1}$ & $\mathrm{~T}_{\mathrm{c} 9}$ & 97 & 65 & $\mathrm{~T}_{\mathrm{s} 5}$ & $\mathrm{~T}_{\mathrm{c} 13}$ & 97 \\
\hline
\end{tabular}

TABLE V. THE PRODUCTION RULES

\begin{tabular}{|c|c|}
\hline № of rules & Production rules \\
\hline 1 & If $t_{v}=T_{v 1}$ and $t_{c}=T c_{1}$, then $\alpha=\alpha_{2}$ and $\alpha=\alpha_{3}^{0.12}$ \\
\hline 2 & If $t_{v}=T_{v 1}$ and $t_{c}=T c_{2}$, then $\alpha=\alpha_{2}^{0.17}$ and $\alpha=\alpha_{3}$ \\
\hline$\cdots$ & $\cdots$ \\
\hline 65 & If $t_{v}=T_{v 5}$ and $t_{k}=T c_{13}$, then $\alpha=\alpha_{5}^{0.12}$ and $\alpha=\alpha_{6}$ \\
\hline
\end{tabular}

Let us consider the first rule: If $t_{v}=t_{V 1}$ and $t c=t_{c l}$ then $\alpha=\alpha_{2}$ and $\alpha=\alpha_{3}{ }^{0.12}$. As can be seen from of this rule consequent (then $\alpha=\alpha_{2}$ and $\alpha=\alpha_{3}{ }^{0.12}$ ), for $a_{2}$, the degree is equal to 1 , whereas for $a_{3}$, it is equal to 0.12 . This means that $a_{2}$ is the basic consequent and $a_{3}$ is the additional one.

So after looking into each of rules separately, the matrix (2) is derived, compiled by the truth degrees of the basic and additional consequential. The column number of the matrix indicates the number of the rule; the line number is the number of the valve opening gap term $\alpha$.

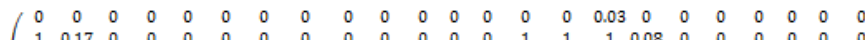

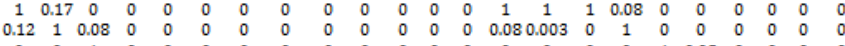

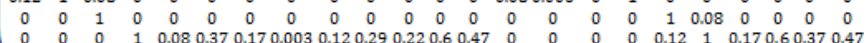

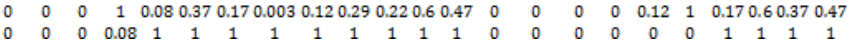

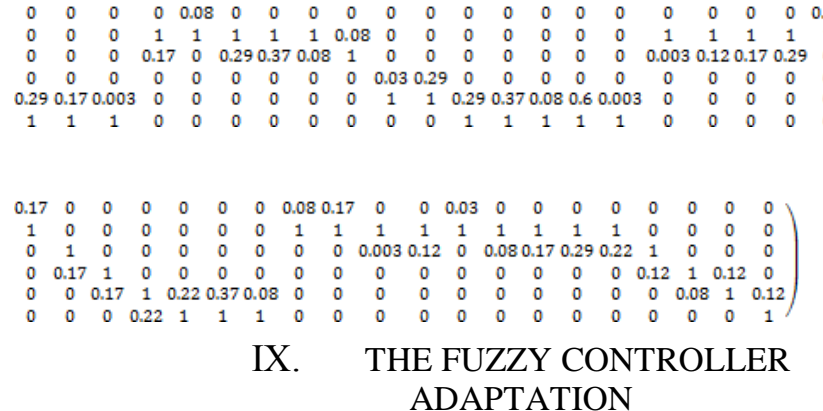

Adaptation will be produced for the developed fuzzy controller by means of a training algorithm.

The gradient descent algorithm, in which as an initial point for algorithm, the Mamdani fuzzy controller can be used, is selected as a training algorithm.

If one denotes the "left" of the terms which are used in the production rule consequents as integer $\mathrm{N}$ t, then the "right" term will have number $(\mathrm{N}+1)$ [5]. The left term is a term with a lower number, that is, in fig. 7. the left term with respect to the other term of a production rule. Therefore, the right term is a term with a larger number being located with respect to another term of the rule on the right side.

Let us introduce the designation:

$$
W=N+v,
$$

where $\mathrm{W}$ - the production rule characteristic, which are obtained from the truth degree values of the basic and additional consequents; i.e. on the basis of this characteristics, one can return to the production rule;

$\mathrm{N}$ - the left term number;

$\mathrm{v}$ - number as determined by the formula:

$$
v=\frac{C+r}{2}
$$

where $r=1$, if the consequent "right" term is used, and $r=$ 0 if the "left" term is applied;

$\mathrm{C}$ - the additional consequent truth degree.

Let us consider the determination of the production rule characteristics using the first rule: If $t_{v}=t_{V 1}$ and $t c=t_{c l}$ then $\alpha=\alpha_{2}$ and $\alpha=\alpha_{3}^{0.12}$.

The left term number is 2 . The additional consequent truth degree $0.12, \mathrm{r}=0$, because it is the left term which is basic. Therefore, one gets the production rule characteristics: $\mathrm{W}_{1}=2+((0.12+0) / 2)=2.06$.

Using the formula (4), let us now get the characteristics of rest production rules from Table $\mathrm{V}: \mathrm{W}_{2}=2+((0.17+0) / 2=$ $2.585 ; \ldots ; \mathrm{W}_{65}=5+((0.12+0) / 2=5.06$.

In the process of the fuzzy controller synthesis, both the basic and additional consequents as well as the additional consequents truth degrees were determined [2, 3]. During determination of truth degree of an additional consequent, the 
reference points were taken as the base (Table V), which represent the maximums of the input linguistic variables terms (fig. 6, 7) $[2,3]$. It is to be understood that in practice, the input parameters can take different values; therefore, the fuzzy controller adaptation must be carried out to allow the controller to be automatically adjusted to match parametric interferences. Based on experimental data, the model (2) has been developed which characterizes the steam spray attemperator operation. Using the developed model, a synthesis of the fuzzy controller was conducted, the production rules were obtained with their characteristic, calculated on the basis of which the fuzzy controller will be adapted. During adaptation, arbitrary values of the steam temperature behind the first stage of superheater $t_{\text {sIst }}$ in the range from $360^{\circ}$ to $400^{\circ} \mathrm{C}$ and condensate temperature $t_{c}$ from $50^{\circ}$ to $110^{\circ} \mathrm{Cwill}$ be used, the outlet steam temperature $\mathrm{t}_{\text {out }}$ may be preset in the range from $270^{\circ}$ to $400^{\circ} \mathrm{C}$.

Arbitrary values of the steam temperature, condensate temperature $t_{\mathrm{sI}}$ and desired outlet steam temperature $\mathrm{t}_{\mathrm{sII}}$ are entered into the model (1); the controller in its turn autimatically adjusts to match variations and produces the current valve for the valve opening gap $\alpha$ (Table VI).

TABLE VI. VALUES CALCULATED BY MEANS OF THE MODEL

\begin{tabular}{|c|c|c|c|c|}
\hline № & $\mathrm{t}_{\mathrm{vI}}$ & $\mathrm{t}_{\mathrm{c}}$ & $\mathrm{t}_{\text {sII }}$ & $\alpha$ \\
\hline 1 & 363 & 54 & 362 & 18 \\
\hline 2 & 365 & 56 & 345 & 40 \\
\hline 3 & 368 & 58 & 310 & 86 \\
\hline 4 & 372 & 63 & 327 & 68 \\
\hline$\ldots$ & $\ldots$ & $\ldots$ & $\ldots$ & $\ldots$ \\
\hline 45 & 399 & 109 & 340 & 68 \\
\hline
\end{tabular}

Let us introduce the designation:

$$
W^{*}=W-\Delta W \cdot \mu\left(C_{p}\right) \cdot \mu\left(C_{k}\right),
$$

where $\mathrm{W}^{*}$-new production rules characteristics as derived from Table VI;

$\mathrm{W}$-production rules characteristics from Table V;

$\mu\left(C_{p}\right) \cdot \mu\left(C_{k}\right)$ - the input variables degree membership, where $\mathrm{Cp}$ is the membership degree of the steamtemperature behind the first stage of superheater $t_{s I s t}, C_{k}$ is the membership degree of the condensate temperature, i.e. $\mathrm{Cp}$ must be multiplied by $\mathrm{C}_{\mathrm{k}}$;

$\Delta \mathrm{W}$ - adaptation step, which is determined by an expert to specify the controller precision.

To create both new production rules and their characteristics, by selecting in turn the lines from Table VI, it is necessary to determine among which terms lie the steam temperature downstream the superheater first stage $t_{\text {sIst }}$ and the condensate temperature $t_{c}$. Further, from the previously obtained rules (Table $\mathrm{V}$ ) one can find the rules, in which terms of the steam temperature $t_{s I}$ and of the condensate temperature $t_{c}$ coincide with those from Table VI. Let us change over to the next production rule using the characteristics of the selected rule and using the formula (4), where $\mathrm{W}$ is substituted by $\mathrm{W}^{*}$.

Thus, in obtaining the production rule characteristics, let us change over to a next rule. New rules are needed to create the fuzzy controller adaptation.

The process of obtaining a new rule:

1) By selecting the 1 st line from VI, one can determine that the steam temperature behind the first stage of superheater $t_{\text {sIst }}$ lies between the TS1 and TS2 terms (fig. 6.), the condensate temperature of $t_{c}$ too lies between the TC1 and TC2 terms. Further, let us find a rule from Table V, where the temperatures occur lying among the same terms numbers. The first production rule from Table $\mathrm{V}$ is now to be selected.

2) At first, one has to determine a new production rule characteristics: $\mathrm{W}_{1} *=2.06-0.15 \cdot 0.7 \cdot 0.1=2.0495$.

3) Using formula (7), one now may calculate it to change over to a new production rule: If $\mathrm{t}_{\mathrm{v}}=\mathrm{T}_{\mathrm{v} 1}$ and $\mathrm{t}_{\mathrm{c}}=\mathrm{T}_{\mathrm{c} 1}$ then $\alpha=\alpha_{2}$ and $\alpha=\alpha_{3}{ }^{0.099}$. Similarly, the remaining 44 production rules (Table VII) are calculated.

TABLE VII.

NEW PRODUCTION RULES AND THEIR CHARACTERISTICS

\begin{tabular}{|c|c|c|}
\hline № & $\begin{array}{l}\text { New production rules } \\
\text { characteristics } \mathrm{W}^{*}\end{array}$ & New production rules \\
\hline 1 & 2.0495 & $\begin{aligned} \text { If } t_{s}=T_{s 1} \text { and } t_{c} & =T c_{1} \text {, then } \alpha=\alpha_{2} \text { and } \\
\alpha & =\alpha_{3} \text {.099 }\end{aligned}$ \\
\hline 2 & 2.5175 & If $\begin{array}{c}t_{s}=T_{s 1} \text { and } t_{c}=T c_{2} \text {, then } \alpha=\alpha_{2}^{0.035} \text { and } \\
\alpha=\alpha_{3}\end{array}$ \\
\hline 3 & 3.042 & If $t_{s}=T_{s 1}$ and $t_{c}=T c_{3}$, then $\alpha=\alpha_{3}$ and $\alpha=$ \\
\hline$\ldots$ & $\ldots$ & \\
\hline 65 & 5.0585 & $\begin{array}{c}\text { If } t_{s}=T_{s 5} \text { and } t_{c}=T c_{13,} \text {, then } \alpha=\alpha_{5} \text { and } \alpha= \\
\alpha_{6} 0.117\end{array}$ \\
\hline
\end{tabular}

The program to control outlet steam temperature $t_{\text {sII }}$ and, as well as the fuzzy controller adaptation, is developed in the software Unity Pro XL using ST language based on PLC Modicon M340. The parameter controlled is the outlet steam temperature downstream of the steam spray attemperator.

\section{CONCLUSION}

Thus, this paper deals with the fuzzy controller synthesis designed to control outlet steam temperature $t_{s I I}$ in the boiler unit. Besides, the fuzzy controller adaptation has been effected based on the method of selection of that consequent in production rules with a double consequent, which is optimal for the current values of the boiler unit parameters.

\section{References}

[1] K.A. Solovyov, E.A. Muravyova, R.G. Sultanov, "The fuzzy controller adaptation", Oil and gas busines, vol. 12-31, pp. 23-128, 2014.

[2] E.A. Muravyova, K.A. Solovyov, M.Z. Mustafina, "The fuzzy controller synthesis with double consequents to control the lubricating station temperature", Oil and gas business, vol.14(4), pp. 172-179, 2016.

[3] K.A. Solovyov, E.A. Muravyova, "Synthesis methods for fuzzy controller with double base of rules", . : Information technologies for intelligent decision-making support. pp. 200-203, May, 2016 
[Proceedings of the 4th International conference: Information technologies for intelligent decision-making support (ITIDS'2016) p. 246, 2016].

[4] E. Muraveva, A. Sagdatullin, A. Emekeev,"Applied Mechanics and Materials" vol. 756, pp. 633-639, 2015.

[5] E.A. Muraveva, K.A. Solovev, O.I. Soloveva, R.G. Sultanov, P.N Charikov, "Key Engineering Materials", vol. 685, pp. 816-822, 2016.

[6] E.A. Muraveva, S.V. Fedorov, A.V. Bondarev, R.R. Kadyrov, E.A. Shulaeva, "Indian Journal of Science and Technology", vol. 8(S10), pp. $1-8,2015$.

[7] L.N. Nedelkovski, N.R. Yurenev, Boiler units of industrial enterprises, 1988.

[8] R.A. Aliev, Production management with fuzzy source informationi, 1991.

[9] V.I. Gostev, Fuzzy controllers in automatic control systems, 2008.

[10] K. Asai, D. Vatada, S. Ivai, Applied Fuzzy Systems, 1993.

[11] P.A. Sakhnyuk, Intellectual systems and technologies, 2012. 